\title{
NOAC versus warfarin in the treatment of atrial fibrillation during the first three months after bioprosthetic aortic valve replacement
}

\author{
Marta Piepiorka-Broniecka ${ }^{1 *}$, Tomasz A. Michalski ${ }^{2 *}$ (®) Tomasz Figatowski \\ Andrzej Wojtowicz ${ }^{1}$, Jarosław Jurowiecki ${ }^{1}$, Aleksandra Stanska ${ }^{3}$, \\ Jan Rogowski ${ }^{1}$, Milosz J. Jaguszewski ${ }^{2}$ \\ ${ }^{1}$ Department of Cardiac and Vascular Surgery, Medical University of Gdansk, Poland \\ ${ }^{2} 1^{\text {st }}$ Department of Cardiology, Medical University of Gdansk, Poland \\ ${ }^{3}$ Division of Quality of Life Research, Department of Psychology, Medical University of Gdansk, Poland
}

This paper was guest edited by Prof. Anna Tomaszuk-Kazberuk

Over 4 million heart valve replacement surgeries have been performed in the last 50 years, and it remains the primary treatment for most patients with significant valve disease. The largest group of complications in these patients are thromboembolic events [1].

Atrial fibrillation (AF) occurs in over $42 \%$ of patients undergoing aortic valve replacement (AVR), which increases the incidence of embolic complications. The administration of vitamin $\mathrm{K}$ antagonists (VKA) is an accepted method of anticoagulant therapy in patients undergoing valve replacement surgery using biological and mechanical prostheses. Recently, a novel 3-month treatment strategy with oral anticoagulants (NOACs) has been approved by the European Society of Cardiology guidelines after bioprosthetic AVR. Reports and guidelines for anticoagulant therapy in the first 3 months after AVR remain inconclusive $[2,3]$. However, there are examples of similar studies in the literature. The study aimed to analyze whether NOACs are non-inferior to VKA in preventing thromboembolic events within the first 3 months following bioprosthetic AVR.

Our pilot study had a prospective, randomized, and open-label design. We enrolled 50 patients who underwent bioprosthetic AVR in the Department of Cardiac and Vascular Surgery, with a history of $\mathrm{AF}$ in the pre-/postoperative period, regardless of previous anticoagulant therapy. The exclusion criterion was the taking of any medications that could increase the risk of bleeding. Patients were assigned to receive NOAC ( $\mathrm{n}=25$ patients) or warfarin ( $\mathrm{n}=25$ patients) in a 1:1 ratio for the first 3 months after surgery (Table 1 ).

The study consisted of three evaluations of the patient's condition. The first took place after AVR, on the discharge day, and included blood tests and transthoracic echocardiography (TTE). Patients were also informed about possible adverse events and the study scheme. At 1-month follow-up, telephone contact was made to obtain information about adverse events, i.e., death, bleeding, and thromboembolic incidents. Three months after enrollment, a follow-up visit took place in the hospital. At this appointment, the following were performed: a detailed anamnesis of adverse events, evaluation of the international normalized ratio (INR) levels in patients treated with VKA, a control TTE, and discussion of the further treatment regimen.

The primary feature assessed in the TTE was the function of the bioprosthesis, visualized by

Address for correspondence: Prof. Milosz J. Jaguszewski, $1^{\text {st }}$ Department of Cardiology, Medical University of Gdansk, ul. Dębinki 7, 80-952 Gdańsk, Poland, tel: +48 512157058, e-mail: jamilosz@gmail.com

Received: 11.06.2021 Accepted: 28.10.2021 Early publication date: 1.12.2021

*These authors contributed equally to this work.

This article is available in open access under Creative Common Attribution-Non-Commercial-No Derivatives 4.0 International (CC BY-NC-ND 4.0) license, allowing to download articles and share them with others as long as they credit the authors and the publisher, but without permission to change them in any way or use them commercially. 
Table 1. Characteristics of patients stratified by treatment, at baseline, on the discharge day, 1 and 3 months after bioprosthetic aortic valve replacement.

\begin{tabular}{|c|c|c|c|c|}
\hline Parameter & $\begin{array}{c}\text { All } \\
(n=50)\end{array}$ & $\begin{array}{l}\text { Warfarin group } \\
\quad(n=25)\end{array}$ & $\begin{array}{l}\text { NOAC group } \\
(n=25)\end{array}$ & $\mathbf{P}$ \\
\hline \multicolumn{5}{|l|}{ Baseline characteristic } \\
\hline Mean age [years] & $67.1 \pm 7.6$ & $68.2 \pm 6.5$ & $65.9 \pm 8.6$ & 0.29 \\
\hline Males & $27(54.0)$ & $13(52.0)$ & $14(56.0)$ & 0.78 \\
\hline Arterial hypertension & $36(72.0)$ & $20(80.0)$ & $16(64.0)$ & 0.21 \\
\hline Coronary artery disease & $14(28.0)$ & $7(28.0)$ & $7(28.0)$ & 1.00 \\
\hline Diabetes mellitus & $11(22.0)$ & $4(16.0)$ & $7(28.0)$ & 0.31 \\
\hline Previous anticoagulants & $13(26.0)$ & $7(28.0)$ & $6(24.0)$ & 0.75 \\
\hline Previous AF & $13(26.0)$ & $7(28.0)$ & $6(24.0)$ & 0.75 \\
\hline $\begin{array}{l}\text { Previous stroke or thromboembolic } \\
\text { incident }\end{array}$ & $1(2.0)$ & $1(4.0)$ & 0 & 0.31 \\
\hline HF with LVEF < 40\% & $3(6.0)$ & $2(8.0)$ & $1(4.0)$ & 0.55 \\
\hline $\mathrm{CHA}_{2} \mathrm{DS}_{2}$-VASc scale* & $3.0(2.0-3.0)$ & $3.0(2.0-3.0)$ & $2.0(1.0-3.0)$ & 0.27 \\
\hline HAS-BLED scale** & $2.0(1.0-2.0)$ & $2.0(1.0-2.0)$ & $1.0(1.0-2.0)$ & 0.14 \\
\hline \multicolumn{5}{|l|}{ Discharge day } \\
\hline Creatinine [mg/dL] & $0.78(0.66-0.99)$ & $0.78(0.65-0.87)$ & $0.77(0.69-1.00)$ & 0.52 \\
\hline Hemoglobin [g/dL] & $9.95(9.30-10.50)$ & $9.7(9.1-10.3)$ & $10.0(9.5-10.8)$ & 0.13 \\
\hline Platelets $\left[\times 10^{9} / \mathrm{L}\right]$ & $206.5(168.0-247.0)$ & $212.0(168.0-247.0)$ & $198.0(177.0-232.0)$ & 0.93 \\
\hline LVEF [\%] & $60.0(51.0-60.0)$ & $60.0(55.0-60.0)$ & $60.0(50.0-60.0)$ & 0.28 \\
\hline $\mathrm{PG}_{\max }[\mathrm{mmHg}]$ & $24.0(17.0-31.0)$ & $27.0(17.0-38.0)$ & $23.0(17.0-26.5)$ & 0.13 \\
\hline $\mathrm{PG}_{\text {mean }}[\mathrm{mmHg}]$ & $14.0(10.0-17.0)$ & $15.0(10.0-20.0)$ & $13.0(10.0-15.0)$ & 0.16 \\
\hline $\mathrm{V}_{\max }[\mathrm{m} / \mathrm{s}]$ & $2.40(2.04-2.80)$ & $2.60(2.04-3.07)$ & $2.40(2.10-2.54)$ & 0.22 \\
\hline $\mathrm{VTI}_{\mathrm{AO}}[\mathrm{cm}]$ & $40.85(36.25-52.90)$ & $39.4(35.5-56.1)$ & $40.95(36.55-51.75)$ & 0.84 \\
\hline $\mathrm{VTI}_{\text {LVOT }}[\mathrm{cm}]$ & $20.40(17.30-23.60$ & $19.2(17.4-23.0)$ & $21.25(17.20-24.25)$ & 0.5 \\
\hline \multicolumn{5}{|l|}{ Phone contact after 1 month } \\
\hline Death & $1(2.0)$ & $1(4.0)$ & 0 & 0.31 \\
\hline Bleeding & $3(6.0)$ & $3(12.0)$ & 0 & 0.07 \\
\hline \multicolumn{5}{|l|}{ Follow-up after 3 months } \\
\hline Death (cumulative) & $1(2.0)$ & $1(4.0)$ & 0 & 0.31 \\
\hline Bleeding (cumulative) & $3(6.0)$ & $3(12.0)$ & 0 & 0.07 \\
\hline LVEF [\%] & $60.0(58.0-63.0)$ & $60.0(59.0-63.0)$ & $60.0(56.5-64.0)$ & 0.95 \\
\hline $\mathrm{PG}_{\max }[\mathrm{mmHg}]$ & $24.8(19.0-30.0)$ & $24.0(18.0-30.0)$ & $26.0(19.5-30.0)$ & 0.91 \\
\hline $\mathrm{PG}_{\text {mean }}[\mathrm{mmHg}]$ & $14.0(10.0-18.0)$ & $13.0(10.0-18.0)$ & $15.0(10.0-18.5)$ & 0.73 \\
\hline $\mathrm{V}_{\max }[\mathrm{m} / \mathrm{s}]$ & $2.50(2.22-2.73)$ & $2.47(2.30-2.73)$ & $2.58(2.18-2.72)$ & 0.72 \\
\hline $\mathrm{VTI}_{\mathrm{AO}}[\mathrm{cm}]$ & $52.05(41.75-62.35)$ & $51.7(42.5-62.3)$ & $52.4(36.6-62.4)$ & 0.83 \\
\hline $\mathrm{VTI}_{\text {LVOT }}[\mathrm{cm}]$ & $24.90(20.40-27.85)$ & $24.9(20.1-27.2)$ & $24.4(20.5-27.9)$ & 0.81 \\
\hline
\end{tabular}

Data are presented as mean \pm standard deviation, median (interquartile range), or counts (percentages).

${ }^{*} \mathrm{CHA}_{2} \mathrm{DS}_{2}$-VASc scale scores reflect the risk of stroke, with values ranging from 0 to 9 , and with higher scores indicating greater risk.

**HAS-BLED scale scores reflect the risk of major bleeding among patients with AF who receive anticoagulant therapy, with values ranging from 0 to 9 , and with higher scores indicating greater risk.

$\mathrm{AF}$ - atrial fibrillation; AVR — aortic valve replacement; HF — heart failure; LVEF — left ventricular ejection fraction; $\mathrm{PG}_{\text {max }}$ - peak aortic

valve pressure gradient; $\mathrm{PG}_{\text {mean }}$ - mean aortic valve pressure gradient; $\mathrm{V}_{\max }$ - peak aortic valve velocity; $\mathrm{VTI}_{\mathrm{Ao}_{0}}-$ aortic velocity time integral; $\mathrm{VTI}_{\mathrm{LVOT}}$ - left ventricular outflow tract velocity time integral

standard echocardiographic parameters, i.e., peak aortic valve pressure gradient $\left(\mathrm{PG}_{\max }\right)$, mean aortic valve pressure gradient $\left(\mathrm{PG}_{\text {mean }}\right)$, peak aortic valve velocity $\left(\mathrm{V}_{\max }\right)$, aortic velocity time integral $\left(\mathrm{VTI}_{\mathrm{Ao}}\right)$, left ventricular outflow tract velocity time integral $\left(\mathrm{VTI}_{\mathrm{LVOT}}\right)$, the overall function of the left ventricle (left ventricular ejection fraction), and the possible amount of fluid in the pericardial sac. 
The factor Xa inhibitor apixaban was selected as an anticoagulant drug in the NOAC group. All patients received the same drug at a dose of $5 \mathrm{mg}$ twice daily, unless there were indications for a reduced dose of $2.5 \mathrm{mg}$ twice daily (creatinine clearance $15-29 \mathrm{~mL} / \mathrm{min}$ or two of the following: age $\geq 80$ years, weight $\leq 60 \mathrm{~kg}$, creatinine $\geq 1.5 \mathrm{mg} / \mathrm{dL}$ ).

The study was approved by the local independent bioethical committee and complied with the Declaration of Helsinki. Written informed consent was obtained from all included patients.

Based on preliminary data, descriptive characteristics were performed for each group. Continuous variables are presented as mean \pm standard deviation or median (interquartile range), and categorical variables as counts (percentages). A t-test or a Mann-Whitney U test was used to compare the continuous variables. Categorical variables were compared using a $\chi^{2}$ test. P-values $<0.05$ were considered statistically significant. Statistical analysis was performed in Statistica 13.3 (StatSoft, TIBCO Software Inc.).

Three (12\%) patients in the warfarin group and none in the apixaban group had a major bleeding incident. Two of them had pericardial effusion, and one had pleural effusion. All 3 patients required hospitalization to perform drainage. One $(4 \%)$ death was reported in the warfarin group and none in the apixaban group. The patient died in hospital 9 days after surgery due to massive pericardial bleeding, probably from heart wall rapture, while adjusting the therapeutic INR. One patient was lost to follow-up.

After 3 months, $60 \%$ of patients in the warfarin group decided to change the anticoagulant treatment on NOAC, mainly due to labile INR. In both groups, there were no bioprosthesis dysfunction findings in the thromboembolic mechanism. We have decided to continue our study by an escalation of the enrollment group.

There is a deficiency of clinical data comparing NOAC and warfarin in the anticoagulant treatment of $\mathrm{AF}$ during the first 3 months after bioprosthetic AVR. Most trials evaluating NOAC vs. warfarin have a heterogeneous group of patients considering different types of valvular heart disease (native valve diseases, bioprosthetic and mechanical valves) or anticoagulation treatment applied $>3$ months postoperatively [4]. The RIVER trial had the most similar model to our study. In this randomized, controlled trial, 1005 patients were enrolled to assess the efficacy and safety of NOAC (rivaroxaban) compared with warfarin in patients after biopros- thetic mitral valve replacement (MVR). However, only 189 patients were randomized up to 3 months after MVR. In this subgroup, the incidence of primary outcome composed of death, major cardiovascular events, or major bleeding after 12 months was $6.4 \%$ in the rivaroxaban group and $18.9 \%$ in the warfarin group. Rivaroxaban was non-inferior to warfarin in patients with $\mathrm{AF}$ and bioprosthetic mitral valve [5].

The results of the RIVER trial support our study findings on the efficacy of NOAC compared to warfarin in patients with $\mathrm{AF}$ after surgical valve replacement with a bioprosthesis. There may also be a potential legitimacy for prescribing chronic anticoagulation in postoperative $\mathrm{AF}$ due to the high safety of NOAC, although $44 \%$ of the subjects were women, and the mean $\mathrm{CHA}_{2} \mathrm{DS}_{2}$-VASc score was 2 . However, further prospective studies on a larger population are required to assess the efficacy and safety of NOACs in patients with $\mathrm{AF}$ and recent ( $<3$ months) bioprosthetic AVR.

In conclusion, in patients with AF during the first 3 months after bioprosthetic AVR apixaban was non-inferior to warfarin for thromboembolic events. Also, apixaban seemed to have a better safety profile than warfarin for the incidence of death or major bleeding.

\section{Conflict of interest: None declared}

\section{References}

1. Durães AR, de Souza Roriz P, de Almeida Nunes B, et al. Dabigatran Versus Warfarin After Bioprosthesis Valve Replacement for the Management of Atrial Fibrillation Postoperatively: DAWA Pilot Study. Drugs R D. 2016; 16(2): 149-154, doi: 10.1007/ s40268-016-0124-1, indexed in Pubmed: 26892845.

2. Mydin MI, Dimitrakakis G, Younis J, et al. Optimal thromboprophylaxis following bioprosthetic aortic valve replacement: still a matter of debate? Interact Cardiovasc Thorac Surg. 2012; 15(1): 109-114, doi: 10.1093/icvts/ivs102, indexed in Pubmed: 22493097.

3. Baumgartner H, Falk V, Bax JJ, et al. 2017 ESC/EACTS Guidelines for the management of valvular heart disease. Eur Heart J. 2017; 38(36): 2739-2791, doi: 10.1093/eurheartj/ehx391, indexed in Pubmed: 28886619.

4. de Souza Lima Bitar Y, Neto MG, Filho JA, et al. Comparison of the New Oral Anticoagulants and Warfarin in Patients with Atrial Fibrillation and Valvular Heart Disease: Systematic Review and Meta-Analysis. Drugs R D. 2019; 19(2): 117-126, doi: 10.1007/ s40268-019-0274-z, indexed in Pubmed: 31055767.

5. Guimarães HP, Lopes RD, de Barros E Silva PGM, et al. Rivaroxaban in Patients with Atrial Fibrillation and a Bioprosthetic Mitral Valve. N Engl J Med. 2020; 383(22): 2117-2126, doi: 10.1056/NEJMoa2029603, indexed in Pubmed: 33196155. 